\title{
Artritis séptica como manifestación inicial de endocarditis bacteriana por Staphylococcus aureus
}

\author{
A. MARTÍNEZ OVIEDO, P. GRACIA SÁNCHEZ, E. PUEO ${ }^{1}$, J. M. CHOPO' \\ Servicios de Medicina Interna y ${ }^{\prime}$ Cardiología. Hospital General Obispo Polanco. Teruel
}

\section{RESUMEN}

Comunicamos un caso de endocarditis bacteriana por Staphylococcus aureus, sobre válvula mitral nativa, en un varón de 80 años, que debutó con una monoartritis séptica, de la articulación glenohumeral, sin manifestaciones cardiológicas iniciales. La respuesta clínica inicial tras drenaje articular y tratamiento antibiótico fue apropiada, pero la aparición de insuficiencia cardiaca recomendó el recambio quirúrgico de la válvula mitral. El paciente falleció súbitamente, el día previo a la intervención.

En la literatura médica (Index Medicus, Medline, Embase, Excerpta Medica hasta 08/2005) están descritos 26 casos, de endocarditis bacteriana con afectación articular inicial, ninguno de ellos séptica, y solamente uno en la articulación glenohumeral.

Queremos incidir en la necesidad de investigar la existencia de endocarditis bacteriana en toda artritis séptica, sin factores de riesgo evidentes, dadas las implicaciones pronosticas y terapéuticas.

PALABRAS CLAVE: Artritis séptica. Endocarditis bacteriana. Staphylococcus aureus.
SEPTIC ARTHRITIS AS AN INITIAL MANIFESTATION OF BACTERIAL ENDOCARDITIS CAUSED BY STAPHYLOCOCCUS AUREUS

\begin{abstract}
We describe a case of Staphylococcus aureus mitral valve endocarditis, in a 80-year-old man who presented with abrupt onset of septic arthritis of the glenohumeral joint, whithout cardiac sintomatology. Fever and articular infection recovery after articular drainage and antimicrobial therapy, but worsening caused by heart failure made valve replacement surgery urgent.He died sudendly before surgery could be done, Until august 2005, in medical literature (Index Medicus, Medline, Embase, Excerpta Medica), we have found 26 cases of bacterial endocarditis with articular infection, as initial manifestation, but none whith septic arthritis and only one in the glenohumeral joint.

This report highligths that unexplained arthritis should alert us to the possibility of bacterial endocarditis because their influence on the clinical management and pronostic implications.
\end{abstract}

KEY WORDS: Septic arthritis. Bacterial endocarditis. Staphylococcus aureus.

Martínez Oviedo A, Gracia Sánchez P, Pueo E, Chopo JM. Artritis séptica como manifestación inicial de endocarditis bacteriana por Staphylococcus aureus. An Med Interna (Madrid) 2006; 23: 184-186.

\section{INTRODUCCIÓN}

Síntomas inespecíficos músculo esqueléticos tales como artralgias y mialgias son frecuentes en pacientes con endocarditis bacteriana (44\%), pero la artritis es relativamente rara (ocurre aproximadamente en el $13 \%$ de los casos) $(1,2)$ afecta fundamentalmente al esqueleto axial y menos a las grandes articulaciones, en cuyo caso la más frecuente es la rodilla $(3,4)$. En la mayor parte de las ocasiones encontramos sinovitis aguda, sin criterios bioquímicos ni bacteriológicos de artritis séptica.

Los traumatismos abiertos son el principal factor de riesgo de artritis infecciosa, seguidos de la inoculación directa y de la presencia de un foco infeccioso adyacente (3). Staphylococcus aureus es el principal responsable, tanto de endocarditis bacteriana sobre válvula nativa, como de artritis séptica en personas mayores de 45 años (5).

Presentamos un paciente cuya, manifestación inicial de endocarditis bacteriana, por Staphylococcus aureus, fue una artritis séptica, sobre la articulación gleno-humeral del hombro derecho. No eran manifiestos los síntomas cardiológicos.

Hasta la actualidad hemos identificado, en la literatura médica (Index Medicus, Medline, Embase, Excerpta Medica) 26 casos similares, de los cuales solamente uno afectaba la articulación del hombro; y en ningún caso la artritis era séptica, ni la manifestación inicial. 


\section{CASO APORTADO}

Varón de 80 años que consultó por fiebre y malestar general de cinco días de evolución. Entre sus antecedentes personales destacaban: Diabetes mellitus tipo 2. Carcinoma espino celular en labio inferior. Doble lesión aórtica degenerativa, esclero-calcificada, con estenosis severa, insuficiencia ligera y función biventricular normal. Arritmia completa por fibrilación auricular en tratamiento anticoagulante. Había rechazado reparación quirúrgica de su valvulopatía aórtica en 2003. Clase funcional actual grado II de la NYHA. Tres días antes percibió, al coger un pequeño peso, dolor en hombro derecho y unas horas después escalofríos, temperatura termometrada de $39^{\circ} \mathrm{C}$, y somnolencia.

En la exploración física resaltó: temperatura $38^{\circ} \mathrm{C}$. Lesión ulcerada de $1 \mathrm{~cm}$ de diámetro en comisura inferior de labio derecho. Semiología de doble lesión aórtica, tumefacción, en región anterior de hombro derecho, con importante limitación de la motilidad y dolor.

En la analítica se apreció leucocitosis: $29.000 \mathrm{~mm}^{3}(80 \%$ neutrófilos). Glucosa $294 \mathrm{mg} / \mathrm{dl}$, albúmina 1,9 g/dl. El ECG mostró AC x FA y bloqueo de rama derecha. La radiografía de tórax evidenciaba engrosamiento peri-bronquial bilateral de predominio central $\mathrm{Rx}$ de hombro derecho: signos artrósicos.

Realizamos artrocentesis de hombro derecho obteniendo 40cc de pus amarillento, compuesto por ingente cantidad de leucocitos polimorfo nucleares; y cocos GRAM positivos identificados como Staphylococcus aureus Germen que aislamos en los hemocultivos, con idéntica sensibilidad antimicrobiana.

Ante el diagnóstico de artritis séptica por $S$. aureus, sin antecedente de lesión invasiva de la articulación, nos planteamos el origen hematógeno a partir de endocarditis bacteriana, hecho que nos confirmó el ecocardiograma transtorácico y transesofágico (Fig. 1) al objetivar en la cara auricular del velo posterior de la válvula mitral, una imagen redondeada e hipermóvil, de 1,6 x $2 \mathrm{~cm}$. compatible con vegetación. En de la unión mitro-aórtica, en tracto de salida de ventrículo izquierdo, se observó una imagen inmóvil sugestiva de absceso, que produce insuficiencia mitral grado II/IV, excéntrica. Válvula aórtica esclero-calcificada con apertura reducida. Gradiente pico 54 $\mathrm{mmHg}$ y medio de $25 \mathrm{mmHg}$. No se observaron vegetaciones dependientes de los velos aórticos. La resonancia magnética de hombro derecho mostró (Fig. 2): derrame articular que produce subluxación de la articulación gleno-humeral, con rotura de la cápsula y extravasación del líquido a partes blandas peri-capsulares. Rotura completa del tendón del supraespinoso, infraespinoso y subescapular. Subluxación del bíceps. Artropatía acromio clavicular.

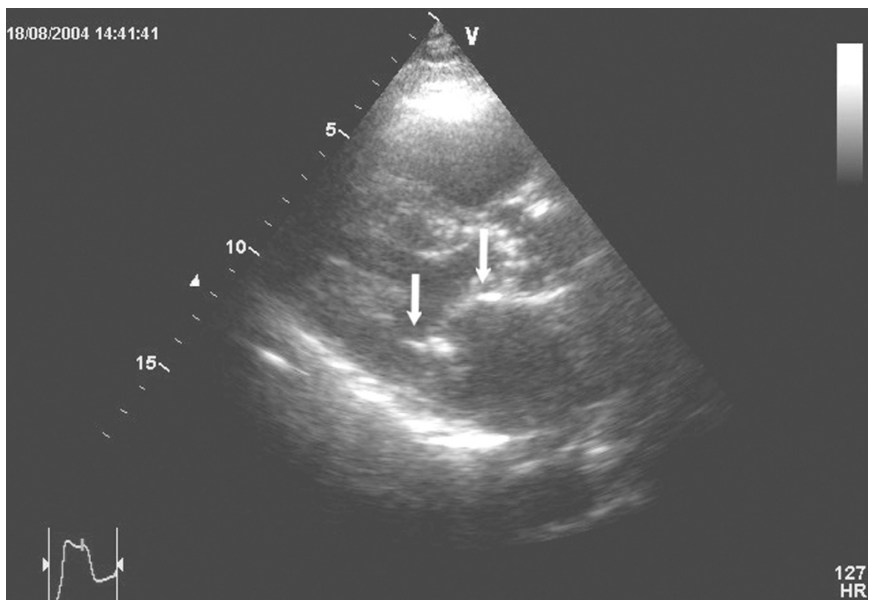

Fig. 1. Imagen de ecocardiograma, plano paraesternal eje largo, donde se objetiva imagen móvil, dependiente del velo posterior mitral, dirigido hacia la aurícula izquierda compatible con vegetación, e imagen sugestiva de absceso en región mitro aórtica (flechas).

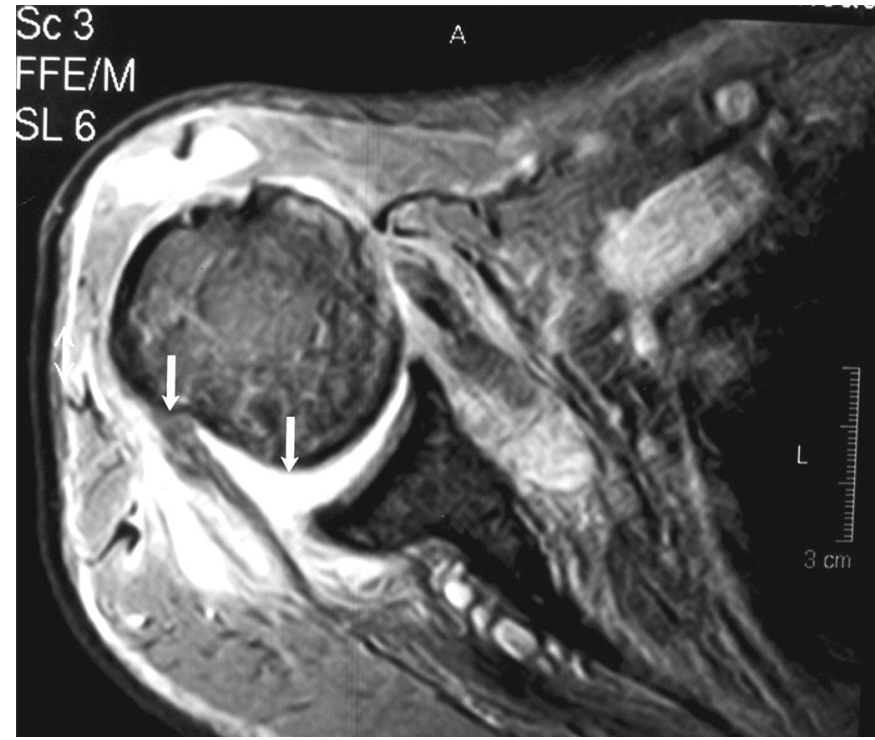

Fig. 2. Resonancia magnética de hombro derecho mostrando derrame articular que produce subluxación de la articulación glenohumeral, con rotura de la cápsula y extravasación del líquido a partes blandas peri-capsulares (flechas).

Ante estos hallazgos se diagnostica al paciente de endocarditis bacteriana precoz con artritis séptica secundaria, asociándose Gentamicina al tratamiento inicial de Cloxacilina. El paciente permanece afebril, desde las 72 horas del ingreso, con negativización de los hemocultivos y mejoría de la sintomatología articular tras nueva artrocentesis Al quinto día aparece clínica de insuficiencia cardiaca que se logra estabilizar, indicándose recambio valvular (6). apoyados por los datos de mal pronóstico (7) se decide tratamiento quirúrgico de la endocarditis si bien fallece de forma súbita, antes de la intervención.

\section{DISCUSIÓN}

Si bien las manifestaciones clínicas aparecieron durante su actividad habitual, sin traumatismo, es presumible que tanto la artropatía acromio clavicular, como las lesiones tendinosas parciales, existieran con anterioridad, como exponente de patología degenerativa del anciano. La clínica aguda probablemente se debió a rotura de la cápsula articular y los tendones del supraespinoso, infraespinoso y bíceps por la infección estafilococica.

La lesión previa del hombro habría favorecido la localización de la infección (3); por mecanismos pro-inflamatorios, que son una llamada eficaz para la colonización bacteriana. Se considera muy frecuentemente que la artritis asociada a endocarditis bacteriana se deba a inmunocomplejos circulantes $(1,2,8)$ como describieron Churchill y cols. y Myers y Commerford. Nuestro paciente nos recuerda la necesidad de descartar la existencia de artritis séptica $(9,10)$, por la importante repercusión terapéutica.

Otro aspecto interesante es la implicación de $S$. aureus como patógeno responsable por ser el más prevalente $(4,5)$ y esperable debido tanto a factores epidemiológicos como clínicos: gravedad, rapidez de progresión, apetencia por el endocardio y la sinovial $(10,11)$ En este caso, es probable que la 
lesión epidermoide del labio fuera la responsable de la bacteriemia por $S$. aureus, aunque dada la ubicuidad de $S$. aureus, y su elevada prevalencia incluso en personas sanas, es difícil de asegurar

Deseamos destacar que, la vegetación dependía del velo posterior de la válvula mitral. Posiblemente la fibrilación auricular, por los flujos anómalos que genera en la aurícula favorece la invasión bacteriana en esta válvula previamente sana. ¿Es la fibrilación auricular un factor de riesgo para la endocarditis bacteriana a tener en cuenta a la hora de hacer profilaxis ante procedimientos invasivos? Como la afectación bacteriana de una válvula aórtica muy esclerocalcificada no es frecuente, debemos pensar como primera opción, en la afectación mitral, si además existe fibrilación auricular.

La presencia de vegetaciones móviles mayores de $10 \mathrm{~mm}$, sumado al absceso de la unión mitro aórtica y la posterior aparición de insuficiencia cardiaca son las responsables de la indicación quirúrgica, en un paciente con múltiples factores de mal pronostico $(6,7)$ elevada edad, albúmina, $<3 \mathrm{~g} / \mathrm{dl}$ diabetes mellitus, e infección por Staphylococcus aureus.

\section{Bibliografía}

1. Churchill MA, Geraci JE, Hunder GG. Musculoskeletal manifestations of bacterial endocarditis. Ann Intern Med 1977; 87: 754-759.

2. Meyer OL, Commerford PJ. Musculoskeletal manifestations of bacterial endocarditis. Ann Rheum Dis 1977; 36: 517-519.

3. Gómez Rodríguez N, Ibáñez Ruán J, González M, Pintado A, Penelas Cortes Y. Artritis sépticas periféricas en adultos. Estudio epidemiológico en un área sanitaria gallega. An Med Interna (Madrid) 2001; 18: 573577.

4. Lossos IS, Yossepotwitch O, Kandel L, et al. Septic arthritis of the glenohumeral joint. A report of 11 cases and review of the Literature. Medicine (Balt) 1998; 77: 177-87.

5. Hogevik H, Olaison L, Andersson R, Lindberg J, Alestig K. Epidemiologic aspects of infective endocarditis in an urban population. A 5-year prospective study. Medicine (Balt) 1995 ; 74:324-39.

6. Bonow Bon, RV Carabello, B, de León, AC, et al. Recommendations for valve replacement with a Bioprosthesis. Circulation 1998; 98 1949-1953.

7. Chu VH, Cabell, Benjamin DK Jr, et al. Early predictors of in-hospital death in infective endocarditis. Circulation 2004; 109: 1745-1749.

8. Nozohoor S, Flock JI, Heimdahl A. Experimental endocarditis in the rat secondary to septic artritis induced by Staphylococcus aureus. Clin Microbiol Infect 1999; 5: 158-163.

9. Suzuki J, Ando H, Nakajima T, et al. Arthritis and Meningitis, the first manifestations of bacterial endocarditis in 2 patients. Jpn Circ J 1997; 61: 450-454.

10. Roberts-Thomson PJ, Rischmueller M, Kwiated RA, Soden M, Ahern MJ, Hilll WR, Geddes RA. Rheumatic manifestations of infective endocarditis. Rheumatol Int 1992; 12: 61-63. 